\title{
euthanasia: a regional perspective
}

It is paradoxical to talk about euthanasia when we are hearing people dying all over the world without willing to die such as in Iraq, Ukraine, Egypt, Palestine and so on. Life is full of contradictions, perplexing complexities, and infinite possibilities. If you ask anyone if he or she wants to die most likely you will get an answer 'no'. On the other hand, we hear every day that people commit suicide. People are committing suicide even though we know that every species instinct is to preserve life. However, we are interested in talking about the process of euthanasia and those people who want to die of their own will or on the advice of others who are near and dear to him/her or claims that they are professional, impartial, honest, competent, and accountable. We are living in a time where choices are limited, independence has become dependence, and freedom is illusory. With these paradoxes, confusions, and unclear ethical and moral principles we want to justify or un-justify euthanasia. It appears that we are going to talk about historicism without knowing historicity. However, we have always tried to move forward even with confusing and unclear directions. Let us see where we get with this.

Euthanasia is a term, which has been in debate for a while in the field of bioethics research. Euthanasia has several forms -voluntary (death at patient's will), involuntary (death at other's will when patient is unconscious or not competent to decide), direct (giving patient direct lethal drug to die), indirect (providing treatment which can expedite patient death), active (death is brought about by an act), and passive (letting someone die either by withdrawing or withholding treatment). ${ }^{1}$ Euthanasia is legal in a few countries such as the Netherland, Belgium, Luxemburg, Norway, and Switzerland (only physician assisted suicide). ${ }^{2}$ In most of the other countries, euthanasia is considered a criminal homicide. In the USA, a few states have recognized active euthanasia as legal such as Oregon, Washington, and Montana. ${ }^{3}$ However, passive euthanasia is considered legal in all USA jurisdictions as it does not involve an act of killing someone rather one is letting someone die on its own naturally. ${ }^{2}$ Do not resuscitate sometimes called "No Code" or "DNR" is a legal order in the United States. ${ }^{4}$ However, in both cases, death is intended. In 1998, Meier et al. in United States gath- ered opinion from 1932 (62\% response from 3200 questionnaires mailed out) physicians to understand the professional opinion on euthanasia. ${ }^{5}$ In that survey, eleven percent physicians said that they support euthanasia and seven percent said that they will give lethal injection. Thirty six percent said that they would do so if it were legal. Eighteen percent said that they have received requests from patients for assisted suicide and 11 percent reported that patients have asked for lethal injection to die during their entire practice career.

In India, euthanasia is not legal and we do not have any research available to understand professionals' opinion. However, in special circumstances courts have adjudicated in favor of passive euthanasia such as in the Aruna Shanbaug case. ${ }^{6}$ In the debate over "right to life" and "right to die", we are aware that "right to life" is not a political right; however, it is ensured by the constitution of India as a fundamental right (Article 21) to avoid its misuse. Any violation of "right to life" comes under the legal preview and people can directly approach the Supreme Court under provisions of Article 32. ${ }^{6}$ Similarly, "right to die" can be misused in several possible ways in India and needs protection through legal/judicial provisions.

Gandhi's position on euthanasia is also in favor of it but only in certain circumstances. ${ }^{7}$ Gandhi was a staunch proponent of Ahimsa (non-violence) due to his religious background; however, he had relativistic approach on euthanasia and endorsed that absolute Ahimsa may not be practical. According to Malloy, physicians, who are religious, are more likely to be idealistic and less relativistic. Indians are more religious and idealistic and less relativistic in thinking. ${ }^{8}$ However, it is not clear if physicians' religious beliefs will not have influence on their attitude, judgment, and decision-making. ${ }^{8}$ On the other hand, given the socioeconomicreligious fabric of India, religiosity and belief systems of relatives of the patient would have a greater influence on euthanasia judgments. Thus, it would be hard to obtain impartial, honest, and moral judgment on euthanasia to protect patient's best interest in India.

I am not trying to assimilate religious argument in reaching the conclusion to support euthanasia. However, it is impor- tant, especially in the Indian context, to see what religion has to say on this issue. Most religious arguments are against euthanasia. ${ }^{9}$ Most of the religions do not approve euthanasia because it defies God's design; however, they approve animal killings except Hinduism (except few sects), Buddhism, and Jainism who advocates Ahimsa (non violence) and even being vegetarian to avoid 'paap' (sin). Contrary to the philosophy of Ahimsa, Hindu ism and Jainism have the concept of "pray opavesa" and "santhara" respectively, which means fasting to death. ${ }^{10}$ It is a form of euthanasia and is accepted by tradition.

As not all homicides are illegal judicially, it appears that not all euthanasia are illegal too. However, the question remains who can decide in favor or against any form of euthanasia and what safety net has to be there to protect patient's best interest. What measures need to be considered to ensure that the patient's who consented for euthanasia was competent. How it can be ensured that the decision made by the family members and/or professionals were impartial and not encouraged by any ulterior motives. The organ transplantation is associated with cases of euthanasia and has greater potential for misuse, especially in India. The decision for euthanasia has to be a collaborative effort of patient, their relatives, physicians, nurses, psychologists, and social workers. All stakeholders will have to decide collectively if the life has reached an end an at. However, social workers can play a bigger role in helping the process as they have the tools and knowledge to connect with patients, families, and their environment. In future, the role of neuroscience will be profound with the development of technology and treatment in helping to decide the cases of euthanasia and organ transplant. ${ }^{11}$

Euthanasia can be a slippery slope in India as it has potential to be misused where dishonesty is a part of the daily-culture, biases are the way of life, and domination is part of life denominations. Euthanasia in India would be uncompromisingly fatal and unobvious-obvious (something which is obvious and people are aware of it, but it does not matter as it does not affect them directly) act of crime, as it can be influenced by dominance, loyalty, socio-economic factors, lack of account- 
ability, and integrity among medical professionals. It can be exasperated by the slow judicial process. It is not a good idea in India to adopt euthanasia as a practice unless it is highly structured, supervised, and in the hand of people who are accountable to immediate justice without manipulation. It appears paradoxical to talk about euthanasia in India, where medical treatment, palliative, and hospice care are inaccessible to most of the people and poor people are forced to practice euthanasia due to inaccessible health care or high cost of medical treatments for them. However, euthanasia in India can be useful in certain circumstances.

\section{Vinod Srivastava}

MA, M.Phil., MSW, LCSW

\section{References}

1. Von Engel hardt D. Euthanasia in history and the present - in the spectrum between euthanasia and terminal care. Acta Historica Leopoldina 2010; 55: 187-212.

2. Shekhar S, and Goel A. Euthanasia: India's Position in the Global Scenario. American Journal of Hospice\& Palliative Medicine 2012; 30(7): 628-631.

3. Steck N, Egger M, Maessen M, et al. Euthanasia and assisted suicide in selected European countries and US states: Systematic literature review. Medical Care, 2013 51(10): 938-944.

4. Chen Y Y, Gordon N H, Connors Jr, A F, et al. Factors associated with two differen protocols of Do-Not-Resuscitate orders in a medical ICU. Critical Care Medicine 2014; 42: 1-9.

5. Meier D E, Anne C A, Allenstein S W, et al. A national survey of physician-assisted suicide and euthanasia in the United States. The New England Journal of Medicine. 1998; 338(17): 1193-1201.
6. Rao S. India and Euthanasia: The poignant case of Aruna Shanbaug. Medical Law Review 2011; 19: 646-656.

7. Joris G. Mahatma Gandhi's view on euthanasia and assisted suicide. Journal of Medical Ethics. 2012; 38: 431-434.

8. Malloy D C, Sevigny P R, Hadji stavropoulos T, et al. Religiosity and ethical Ideology of Physicians: A Cross-Cultural Study. J Relig Health. 2014; 53: 244-254.

9. Zehnder P W, Royse D. Attitude toward assisted suicide: A survey of Hospital Volunteers.1999; 14 (2): 49-63.

10. BBC: Religion [Internet]. 2009. [Cited 2014 Jul 29] Euthanasia, assisted dying, and suicide. Available from http://www.bbc. co.uk/religion/religions/hinduism/hinduethics/euthanasia.shtml.

11. Pandya, S. K. Medical Ethics in Neurosciences. Neurology India 2003; 51(3): 317-22.

doi : $10.5214 /$ ans. 0972.7531 .210302 